\title{
Effect of Nanoparticles Size and Concentration on Thermal and Rheological Properties of $\mathrm{AL}_{2} \mathrm{O}_{3}$-Water Nanofluids
}

\author{
Roy Jean Issa \\ West Texas A\&M University \\ Canyon, Texas, U.S.A. \\ rissa@wtamu.edu
}

\begin{abstract}
An experimental study was conducted to investigate the thermal and rheological properties of various suspensions of $\mathrm{AL}_{2} \mathrm{O}_{3}$ in deionized water. Tests were carried out using nanoparticles with average diameters of 5 and $50 \mathrm{~nm}$ for suspensions concentration ranging from 0 to $40 \%$ by mass. Tests reveal that alumina nanofluids thermal conductivity increases with the in crease in operating temperature and in suspensions concentration, but decreases with the increase in nanoparticles diameter. Also, fluids with 5 $\mathrm{nm}$ particles exhibit non-Newtonian characteristics of shear thinning fluids. This behaviour intensifies as the suspensions concentration increases. However, fluids with $50 \mathrm{~nm}$ particles behave as shear thickening fluids. This behaviour does not seem to be altered by the increase in suspensions concentration. Tests also reveal that alumina nanofluids viscosity increases with the increase in the suspensions concentration. For fluids with $5 \mathrm{~nm}$ particles, viscosity is shown to increase with the increase in the operating temperature, but for fluids with $50 \mathrm{~nm}$ particles it is shown to decrease with the increase in temperature.
\end{abstract}

Keywords: nanofluid, nanoparticle, thermal conductivity, viscosity, non-Newtonian

\section{Introduction}

Thermal conductivity of $\mathrm{AL}_{2} \mathrm{O}_{3}$-water nanofluids have been experimentally examined in the past few years. However, there is a wide variation in the reported values among different authors. Very few researchers have examined the effect of using different particle sizes. Lee et al. [1] conducted studies on the thermal conductivity of dilute $\mathrm{AL}_{2} \mathrm{O}_{3^{-}}$ water nanofluids in a concentration range of 0.01 to $0.3 \%$ by volume using $30 \mathrm{~nm} \mathrm{AL}_{2} \mathrm{O}_{3}$ particles. Their results showed an enhancement of $1.4 \%$ at $0.3 \%$ volume concentration. Chandrasekar et al. [2] performed tests for a larger concentration range of 0.3 to $3 \%$ by volume using $43 \mathrm{~nm}$ particles. The enhancement in thermal conductivity was about $10 \%$ for the concentration of $3 \%$ by volume. Mintsa et al. [3] investigated the effect of two different alumina particle sizes (36 and 47 $\mathrm{nm}$ ) on the nanofluid thermal conductivity for concentrations ranging from 0 to $18 \%$ by volume. Their study showed the nanofluid thermal conductivity to increase with the decrease in nanoparticles size. At $18 \%$ volume concentration, the enhancement in the thermal conductivity of the nanofluid was about $30 \%$ for $36 \mathrm{~nm}$ particles, and $25 \%$ for $47 \mathrm{~nm}$ particles. A study performed by Das et al. [4] using $38.4 \mathrm{~nm}$ particles showed $9 \%$ enhancement in thermal conductivity at $4 \%$ volume concentration, while experiments performed by Ghanbarpour et al. [5] showed a much higher thermal conductivity enhancement. Their thermal conductivity enhancement was $16 \%$ at $4 \%$ volume concentration, and $88 \%$ at $12 \%$ volume concentration. Ghanbarpour et al. used larger alumina nanoparticles $(75 \mathrm{~nm})$. The study conducted by Duan [6] on nanofluid concentrations ranging from 0 to $5 \%$ by volume showed comparable results to Ghanbarpour et al. for that range. However, the nanoparticles he investigated were much smaller $(25 \mathrm{~nm})$. Eastman et al. [7] performed their tests in the same concentration range as Duan but with slightly larger particles $(33 \mathrm{~nm})$. The thermal conductivity enhancement was higher (24\% at $4 \%$ volume concentration). On the other hand, Yiamsawasd et al. [8] reported a much lower enhancement of only $11 \%$ at $4 \%$ volume concentration for their $120 \mathrm{~nm}$ alumina particles. All of the above researchers have conducted their studies at room temperature with the exception of Mintsa et al. and Yiamsawasd et al. who have performed their tests at slightly elevated temperatures of 30 to $40{ }^{\circ} \mathrm{C}$. There is contradiction among various researchers. For example, Lee et al. [1], Mintsa et al. [3], Das et al. [4] and Eastman et al. [7] have used comparable alumina nanoparticles ranging from 30 to $38 \mathrm{~nm}$ but have reported a wide variable in thermal conductivity where Mintsa et al. data were at the low end of values, and Eastman et al. data were at the high end. Also, inconsistencies are shown in the comparison of the data between Chandrasekar et al. [2] and Mintsa et al. [3] for their comparable nanoparticle size range of 43 to $47 \mathrm{~nm}$. In addition, very 
limited studies have investigated the effect of nanoparticle size on nanofluid thermal conductivity enhancement. The current study aims at resolving some of these issues by analyzing the thermal conductivity of alumina-in-water nanofluids, and the effect nanoparticles size have on the nanofluids thermal conductivity enhancement.

With regard to alumina-in-water viscosity, open literature review shows the research conducted on this nanofluid is still scare. Some of the researchers who investigated alumina-in-water nanofluid viscosity include Timofeeva et al. [9], Murshed et al. [10], Nguyen et al. [11], and Yiamsawasd et al. [8]. These researchers have tested nanoparticles ranging in size from 11 to $75 \mathrm{~nm}$. The majority of these researchers have investigated larger nanoparticles with the exception of Timofeeva et al. who were the only ones to examine the effect of nanoparticles as fine as $11 \mathrm{~nm}$. Murshed et al. and Chandrasekar et al. have tested concentrations up to $5 \%$ by volume, and their results showed a viscosity increase between 80 to $140 \%$, while the other researchers have increased their concentrations to $10 \%$ by volume and their viscosity has increased between 114 and $180 \%$. The aim of this study is to expand on these findings.

\section{Experimental Setup}

The thermal conductivity of various suspensions of $\mathrm{AL}_{2} \mathrm{O}_{3}$ in deionized water was measured using a KD2 Pro thermal properties analyzer by Decagon Devices. The analyzer consists of a microcontroller with several needle sensors that can be used. KS-1 sensor needle was selected to determine the thermal conductivity of the nanofluids. The needle contains both a heating element and a thermistor. The needle, $1.3 \mathrm{~mm}$ in diameter and $6 \mathrm{~cm}$ long, was inserted vertically (to minimize natural convection) inside a test tube containing the nanofluid sample (Fig. 1). Heat was applied to the single needle for a short duration of time, and the temperature was monitored in the needle for an additional time after heating was turned off. The total time duration for each test was about 1 minute. The fluid sample was heated by a temperaturecontrolled water bath that was insulated from the surroundings. Tests were carried out after the desired steady state temperature of the fluid was reached. KD2-Pro thermal conductivity measurements are sensitive to temperature changes, and for this reason all measurements were done in a water bath. To eliminate forced vibration in the fluids, tests were carried out in the quiet evenings on a specially built vibration isolation table and away from environmental disturbances that are caused by systems such as HVAC, fans, electronic devices, and daily people activity. Repeated test measurements were performed on each nanofluid sample. Averaged values and uncertainty in the experimental determination of thermal conductivity were obtained.

Rheology tests were conducted on suspensions of $\mathrm{AL}_{2} \mathrm{O}_{3}$ in deionized water using a specially built UL adapter attached to LVDV-II+Pro Brookfield digital viscometer (Fig. 2). The UL adapter measures viscosities as low as 1 centipoise. Newtonian and non-Newtonian fluids can be tested. The UL adapter consists of a precision cylindrical spindle rotating inside an accurately machined tube that contains the $16 \mathrm{ml}$ fluid test sample. A water jacket for accurate temperature control surrounds the tube.

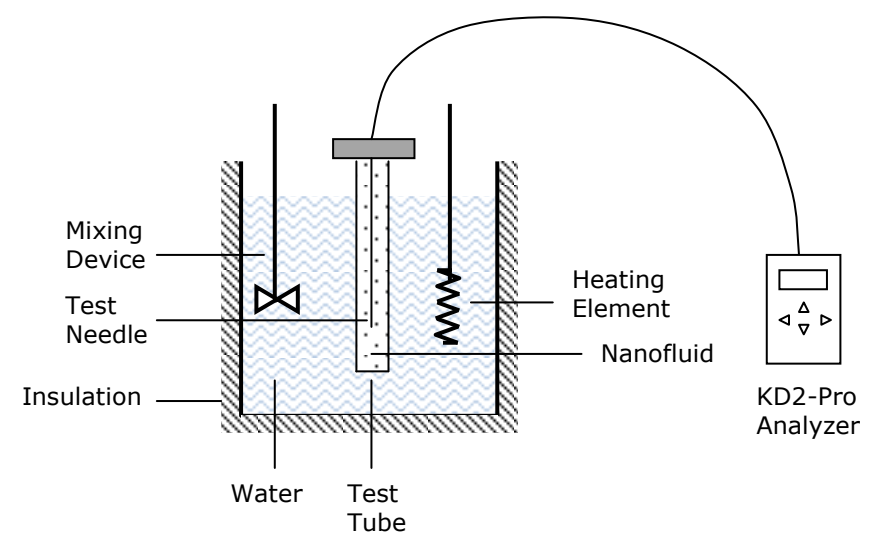

Fig. 1: Experimental setup for thermal conductivity analysis.

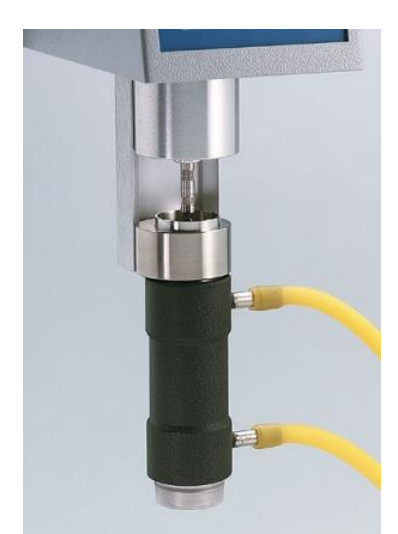

Fig. 2: LVDV-II+Pro viscometer (UL adapter). 


\section{Results and Discussion}

\subsection{Thermal Conductivity Measurements}

Nanofluid test samples using 5 and $50 \mathrm{~nm}$ alumina particles of various concentrations were prepared and tested in a laboratory experimental setup for the determination of thermal conductivity. Figures 3 and 4 show the average thermal conductivity of repeated test measurements on 5 and $50 \mathrm{~nm} \mathrm{AL} \mathrm{O}_{3}$ suspensions in deionized water, respectively. Tests were carried out at two different fluid temperatures $\left(21.8-23{ }^{\circ} \mathrm{C}\right.$, and $\left.46-46.5{ }^{\circ} \mathrm{C}\right)$, and for nanoparticles concentrations ranging from 0 to $20 \%$ by mass for the $5 \mathrm{~nm}$ suspensions, and from 0 to $40 \%$ by mass for the $50 \mathrm{~nm}$ suspensions. Figures 3 and 4 show the error bars associated with repeated tests. Tests reveal that the thermal conductivity of the nanofluid increases with the increase in fluid temperature, and also increases with the increase in $\mathrm{AL}_{2} \mathrm{O}_{3}$ mass concentration. A comparison in thermal conductivity values between Figs. 3 and 4 shows that a decrease in alumina naoparticle size results in an increase in the thermal conductivity of the nanofluid. For the same mass concentration, as the particle size decreases, the number of particles in the base fluid increases causing an increase in the surface area between the solid and the liquid phase, thus resulting in an increase in the effective thermal conductivity. Results show thermal conductivity increases by about $33 \%$ for the case of $50 \mathrm{~nm}$ particles and $46{ }^{\circ} \mathrm{C}$ water bath temperature as the mass concentration increases from 0 to $20 \%$. For the case of $5 \mathrm{~nm}$ particles and $46.5{ }^{\circ} \mathrm{C}$ water bath temperature, the increase in mass concentration from 0 to $20 \%$ results in an increase of about $38 \%$ in thermal conductivity. The decrease in alumina particle size from 50 to $5 \mathrm{~nm}$ results in an average increase of about $5 \%$ in thermal conductivity for the mass concentration range of 0 to $20 \%$. The uncertainty in the determination of thermal conductivity is shown to increase with the increase in the suspensions concentration.

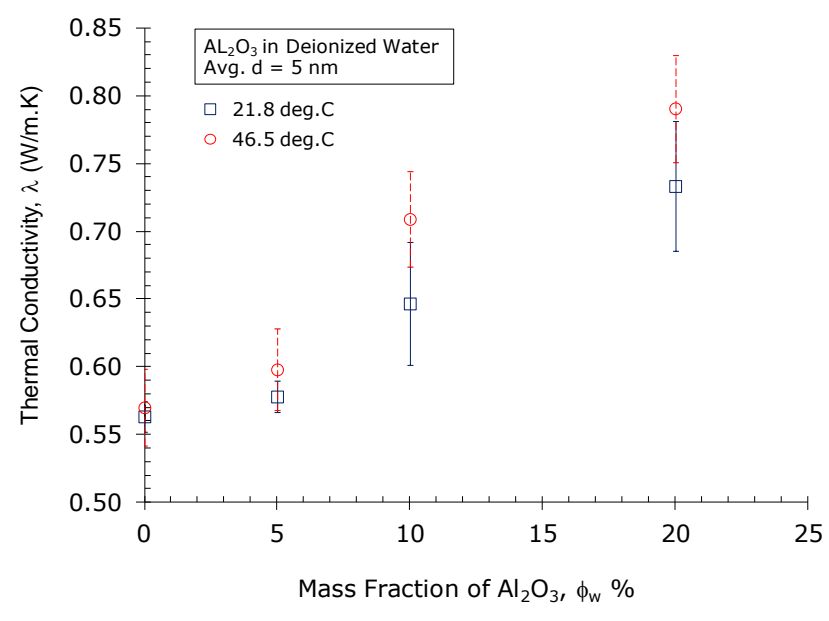

Fig. 3: Nanofluid thermal conductivity versus $\mathrm{AL}_{2} \mathrm{O}_{3}$ concentration by mass ( $5 \mathrm{~nm}$ particles).

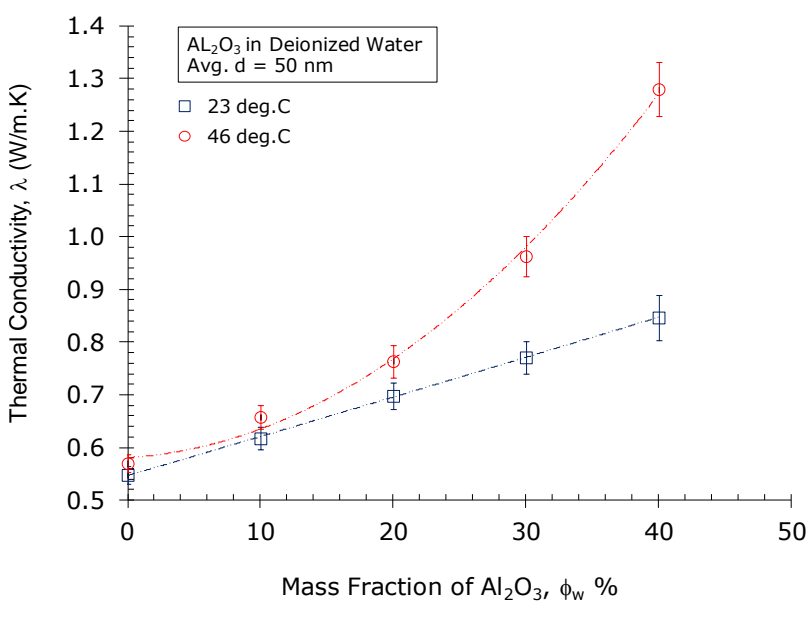

Fig. 4: Nanofluid thermal conductivity versus $\mathrm{AL}_{2} \mathrm{O}_{3}$ concentration by mass ( $50 \mathrm{~nm}$ particles).

Thermal conductivity of the nanofluids is estimated from the temperature history obtained by the thermal property analyzer using the relationship proposed by Carslaw and Jaeger [12]:

$$
\lambda=\frac{q}{4 \pi L} \frac{d \ln t}{d \Delta T}
$$

Where $\lambda$ is the fluid thermal conductivity of the nanofluid, $q$ is the heating energy in the needle sensor, $L$ is the length of the hot wire, $t$ is time, and $T$ is temperature.

\subsection{Specific Heat Measurements}

Calorimetric tests were conducted on the test samples to determine their specific heat (quenching of steel in waterbased nanofluids with alumina). The following equation was used to estimate the specific heat of a nanofluid sample, $c_{n f}$ : 


$$
c_{n f}=\frac{m_{s} c_{s}}{m_{n f}} \frac{T_{i, s}-T_{n f, f}}{T_{n f, f}-T_{n f, i}}
$$

Where $T_{n f, i}$ is the initial temperature of the nanofluid sample, $T_{n f, f}$ is the final temperature of the nanofluid sample, $T_{i, s}$ is the initial temperature of the stainless steel sphere used in the calorimeter, $c_{s}$ is the specific heat of the sphere, $m_{s}$ is the mass of the spheres, and $m_{n f}$ is the mass of the nanofluid sample. Figure 5 shows the specific heat of the nanofluid samples for the case of 5 and $50 \mathrm{~nm}$ particles as function of the particles mass concentration. The results show the specific heat to decrease with the increase in particles mass concentration. As the concentration increases from 0 to $20 \%$, the decrease in the specific heat is by about $15 \%$ for the case of $50 \mathrm{~nm}$ suspensions and by about $20 \%$ for the case of $5 \mathrm{~nm}$ suspensions. It is also observed that as the nanoparticles size decreases from 50 to $5 \mathrm{~nm}$, the specific heat decreases by an average of $5 \%$.

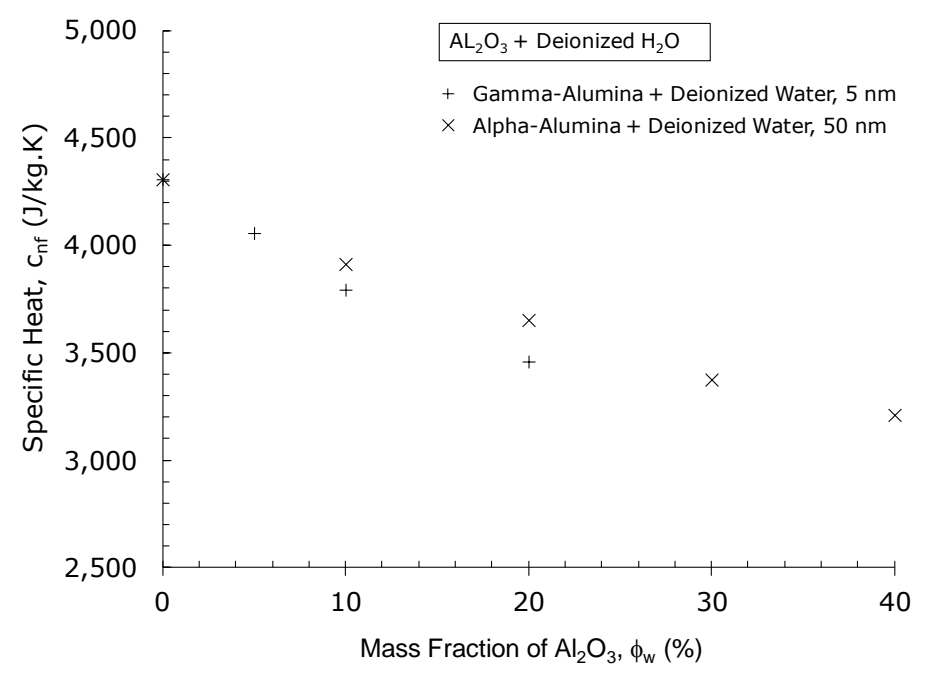

Fig. 5: Nanofluid specific heat versus $\mathrm{AL}_{2} \mathrm{O}_{3}$ concentration by mass.

\subsection{Rheological Property Measurements}

Rheological tests were conducted on the same samples originally used for thermal property evaluation. Rheological properties were conducted using UL adapter attached to LVDVII+Pro viscometer. Suspensions were mixed thoroughly using a high-speed mixing device for about 30 minutes before the viscosity tests were carried out. All tests were performed at room temperature ranging from 18 to $18.5^{\circ} \mathrm{C}$, and at an elevated temperature ranging from 45 to $47{ }^{\circ} \mathrm{C}$ using a water bath. Figure 6 shows the variation in the nanofluid viscosity as function of the shear rate, nanoparticles concentration, and operating temperature for the case of $5 \mathrm{~nm}$ particles. Figure 7 shows similar results for the case of 50 $\mathrm{nm}$ particles. Suspensions with $5 \mathrm{~nm}$ particles show a decrease in viscosity with the increase in shear rate. The viscosity is shown in Fig. 6 to decrease by a factor of 10 as shear rate increases by a factor of 100. This is a typical behaviour for a shear thinning fluid (pseudoplastic behaviour). For these nanofluids, viscosity increases with both particles concentration and operating temperature. However, suspensions with $50 \mathrm{~nm}$ particles show some increase in viscosity with the increase in shear rate; thus, a shear thickening fluid behaviour (dilatant fluid). The maximum increase in viscosity seen in Fig. 7 is by a factor of about 2 for a shear rate increase by a factor of 3 . Figures 8 and 9 show the shear stress as function of shear rate, concentration and temperature for the 5 and $50 \mathrm{~nm}$ particles suspensions, respectively. 


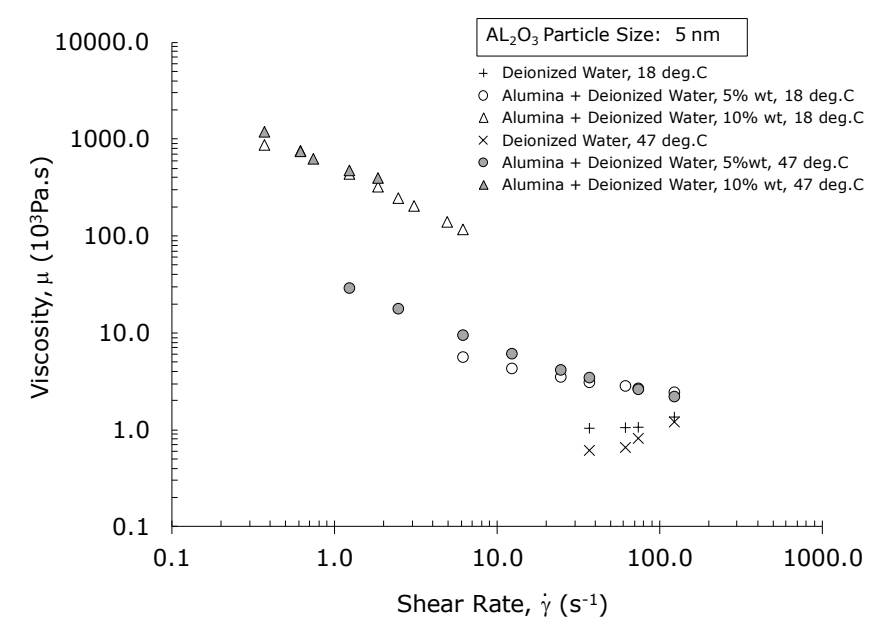

Fig. 6: Viscosity versus shear rate (5 $\mathrm{nm}$ particles).

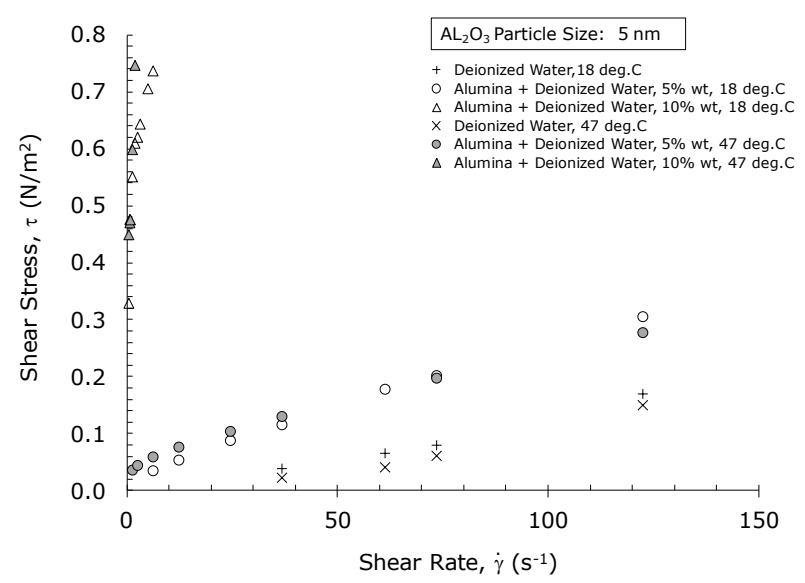

Fig. 8: Shear stress versus shear rate (5 $\mathrm{nm}$ particles).

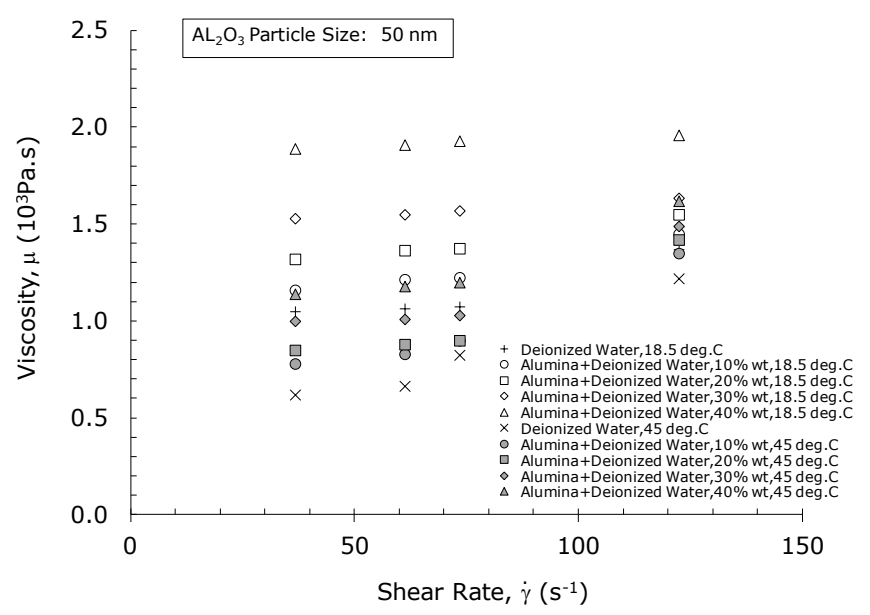

Fig. 7: Viscosity versus shear rate (50 $\mathrm{nm}$ particles).

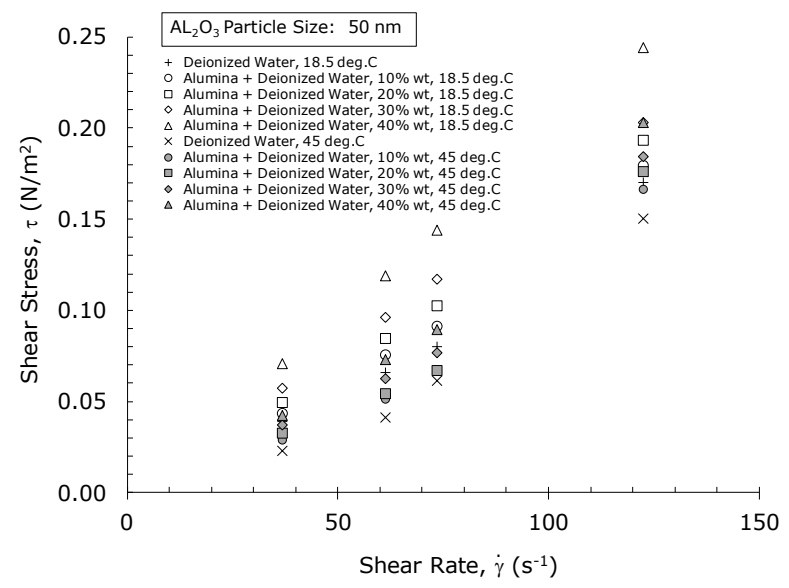

Fig. 9: Shear stress versus shear rate (50 $\mathrm{nm}$ particles).

For the case of $5 \mathrm{~nm}$ particles suspensions (Fig. 8), the fluids are shown to exhibit non-Newtonian flow behaviour. This relationship can be represented by the power law or Ostwald-de-Wale equation:

$$
\tau=K \dot{\gamma}^{n}
$$

Where $K$ is a consistency coefficient and $n$ is the power law index of the flow. $n$ can be experimentally determined from the slope of the double logarithmic plot for the viscometer motor torque, $T_{m}$, versus spindle angular velocity, $\omega$ :

$$
n=\frac{d \ln T_{m}}{d \ln \omega}
$$

$n$ is less than 1 for pseudoplastic fluids, greater than 1 for dilatants fluids, and equal to 1 for Newtonian fluids. For the case of $5 \mathrm{~nm}$ particles suspensions (Fig. 8), as the particles mass concentration increases from 5 to $10 \%$, the fluids nonNewtonian characteristics intensify. For mass concentrations of $10 \%$, the fluids behave as Bingham pseudoplastic where a finite yield stress is required before the fluids begin to flow. However, for the case of $50 \mathrm{~nm}$ particles suspensions (Fig. 9), the fluids exhibit slight non-Newtonian characteristics. The increase in concentration does not seem to alter this behaviour. 
Table 1 shows the calculated power law index (for the test cases in Figs. 6 through 9) to vary from 0.25 to 0.72 for the $5 \mathrm{~nm}$ particles and from 1.03 to 1.45 for the $50 \mathrm{~nm}$ particles revealing shear thinning and shear thickening behaviours.

Table 1: Calculated power law index parameters for the nanofluids.

\begin{tabular}{|c|c|c|c|c|c|}
\hline $\begin{array}{c}\text { Nanoparticles } \\
\text { Size }(\mathrm{nm})\end{array}$ & $\begin{array}{c}\text { Mass } \\
\text { Concentration } \\
(\%)\end{array}$ & $\begin{array}{c}\text { Fluid } \\
\text { Temperature } \\
\left({ }^{\circ} \mathrm{C}\right)\end{array}$ & $\begin{array}{c}\text { Power Law } \\
\text { Index, } n\end{array}$ & $\begin{array}{c}\text { Consistency, } \\
K \\
\left(\mathrm{x} 10^{3}\right)\end{array}$ & $\begin{array}{c}\text { Least Square } \\
\text { Fit, }^{2}\end{array}$ \\
\hline 5 & 5 & 18.0 & 0.722 & 9.080 & 0.997 \\
\hline 5 & 10 & 18.0 & 0.253 & 490.1 & 0.910 \\
\hline 5 & 5 & 47.0 & 0.433 & 29.38 & 0.976 \\
\hline 5 & 10 & 47.0 & 0.325 & 574.0 & 0.888 \\
\hline 50 & 10 & 18.5 & 1.171 & 0.625 & 0.996 \\
\hline 50 & 20 & 18.5 & 1.128 & 0.835 & 0.997 \\
\hline 50 & 30 & 18.5 & 1.049 & 1.303 & 1.000 \\
\hline 50 & 40 & 18.5 & 1.027 & 1.749 & 1.000 \\
\hline 50 & 10 & 45.0 & 1.448 & 0.145 & 0.982 \\
\hline 50 & 20 & 45.0 & 1.390 & 0.197 & 0.964 \\
\hline 50 & 30 & 45.0 & 1.322 & 0.292 & 0.976 \\
\hline 50 & 40 & 45.0 & 1.294 & 0.377 & 0.984 \\
\hline
\end{tabular}

\subsection{Comparison with other Studies}

Figure 10 shows a comparison in the thermal conductivity of alumina-in-water nanofluids between the current study and other studies. The results of the current study compared well with those of Eastman et al. [7] and Ghanbarpour et al. [5]. The current study and Eastman et al. used the transient hot wire method for determining thermal conductivity, while Ghanbarpour et al. used the transient plane source method and a surfactant in the nanofluid. These studies showed much higher thermal conductivities than the other studies in the figure. For example, the study by Mintsa et al. [3] was also based on the transient hot wire method, but their thermal conductivity was much lower. In their tests, a mixer was embedded all the time at a very close proximity to the sensor and may have altered the data. However, results of others such as Duan [6], who also used the transient hot wire method and a surfactant, were not too far off.

Figure 11 shows a comparison in the viscosity of alumina-in-water nanofluids between various studies. For the case of $50 \mathrm{~nm}$ particles, the results of the current study compared well with those of Ghanbarpour et al. [5] and Nguyen et al. [11], but were not far off from the results of others as long as the particles size was between 40 and $75 \mathrm{~nm}$. However, for the case of $5 \mathrm{~nm}$ particles, the results of the current study showed the nanofluid becoming extremely viscous with the increase in particles concentration. Research using very fine particles is scare except those by Timofeeva et al. [9] for 11 $\mathrm{nm}$ particles. For these very fine particles, a similar trend in the viscosity behaviour is shown.

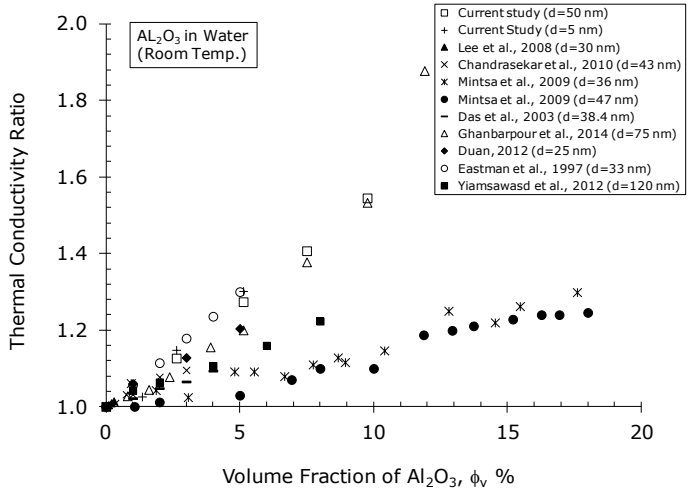

Fig. 10: Thermal conductivity comparison between various studies.

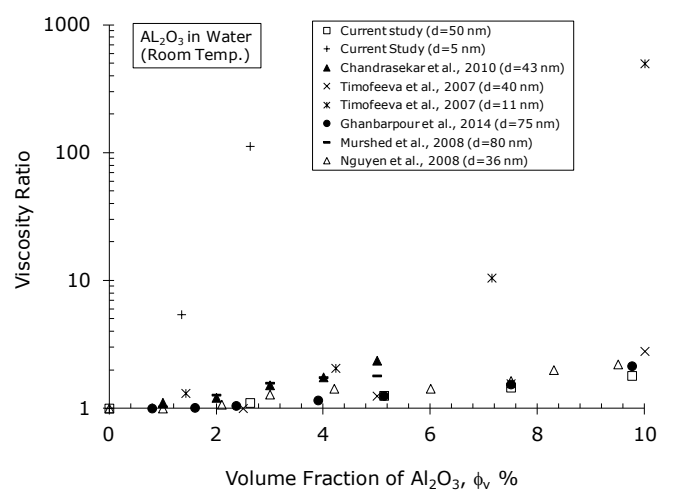

Fig. 11: Viscosity comparison between various studies. 


\section{Conclusion}

An experimental study was conducted to investigate the thermal and rheological properties of alumina-in-water nanofluids. Tests were carried out on suspensions concentration ranging from 0 to $40 \%$ by mass and for particle sizes of 5 and $50 \mathrm{~nm}$. Tests reveal that as the mass concentration increases from 0 to $20 \%$, thermal conductivity increases by about $33 \%$ for the $50 \mathrm{~nm}$ particles and by about $38 \%$ for the $5 \mathrm{~nm}$ particles. The decrease in nanoparticle size results in about $5 \%$ improvement in bulk thermal conductivity. Specific heat is shown to decrease with the increase in nanoparticles concentration, and also to decrease with the decrease in nanoparticles size. Rheological tests on suspensions using $5 \mathrm{~nm}$ particles show a sharp decrease in viscosity with the increase in shear rate (pseudoplastic behaviour). The decrease in viscosity is by about a factor of 10 as shear rate increases by a factor of 100 . However, suspensions using $50 \mathrm{~nm}$ particles show an increase in viscosity with the increase in shear rate (dilatant fluid). The maximum increase in viscosity is by a factor of less than 2 as shear rate increases by a factor of 3 . The decrease in particle size from $50 \mathrm{~nm}$ to $5 \mathrm{~nm}$ causes an increase in viscosity by as much as $1000 \%$ at very low shear rates. Viscosity is also shown to increase with both particles concentration and operating temperature.

\section{Acknowledgements}

The author would like to thank Mr. Bryan Utley, undergraduate student in the Mechanical Engineering Department at West Texas A\&M University, for assisting in some of the data collection for this study.

\section{References}

[1] J.H. Lee et al., "Effective viscosities and thermal conductivities of aqueous nanofluids containing low volume concentrations of $\mathrm{AL}_{2} \mathrm{O}_{3}$ nanoparticles," Int. J. Heat Mass Transfer, vol. 51, no. 11-12, pp. 2651-2656, 2008.

[2] M. Chandrasekar et al., "Experimental investigations and theoretical determination of thermal conductivity and viscosity of $\mathrm{AL}_{2} \mathrm{O}_{3}$ /water nanofluid," Exp. Therm. Fluid Sci., vol. 34, no. 2, pp. 210-216, 2010.

[3] H.A. Mintsa et al., "New temperature dependent thermal conductivity data for water-based nanofluids," Int. J. Therm. Sci., vol. 48, no. 2, pp. 363-371, 2009.

[4] S.K. Das et al., "Temperature dependence of thermal conductivity enhancement for nanofluids," J. Heat Transfer, vol. 125 , no. 4, pp. 567-574, 2003.

[5] M. Ghanbarpour et al., "Thermal properties and rheological behaviour of water based $\mathrm{AL}_{2} \mathrm{O}_{3}$ nanofluid as a heat transfer fluid," Exp. Therm. Fluid Sci., vol. 53, pp. 227-235, 2014.

[6] F. Duan, "Thermal property measurement of $\mathrm{AL}_{2} \mathrm{O}_{3}$-water nanofluids," in Smart Nanoparticles Technology, A. Hashim, Ed. Croatia: InTech Europe, 2012, pp. 335-357.

[7] J.A. Eastman et al., "Enhanced thermal conductivity through the development of nanofluids," in Materials Research Society Symposium Proceedings, Boston, MA, 1997, vol. 457, pp. 3-11.

[8] T. Yiamsawasd et al., "Measurement of the thermal conductivity of titania and alumina nanofluids," Thermochim. Acta, vol. 545, pp. 48-56, 2012.

[9] E.V. Timofeeva et al., "Thermal conductivity and particle agglomeration in alumina nanofluids: Experiment and theory," Phys. Rev. E, vol. 76, pp. 1-16, 2007.

[10] S.M.S. Murshed et al., "Investigations of thermal conductivity and viscosity of nanofluids," Int. J. Therm. Sci., vol. 47, no. 5, pp. 560-568, 2008.

[11] C.T. Nguyen et al., "Viscosity data for $\mathrm{AL}_{2} \mathrm{O}_{3}$-water nanofluid hysteresis," Int. J. Therm. Sci., vol. 47, no. 2, pp. 103$111,2008$.

[12] H.S. Carslaw and J.C. Jaeger, Conduction of Heat in Solids. New York, NY: Oxford University Press, 1959. 